\title{
Multimodalidad y discurso educativo ${ }^{1}$
}

\author{
Multimodality and Educational Discourse ${ }^{2}$
}

\author{
Dulce María Santamaría ${ }^{3}$ \\ Universidad Pedagógica Experimental Libertador-Instituto Pedagógico de Caracas \\ Departamento de Castellano, Literatura y Latín Cátedra de Español Instrumental \\ Caracas, Venezuela \\ dulsam6@hotmail.com
}

Recibido 1 de mayo de 2014 • Corregido 21 de febrero de 2015 • Aceptado 27 de abril de 2015

\begin{abstract}
Resumen. El presente artículo toca la multimodalidad y el entorno educativo. En él se hace un análisis de esta disciplina y de cómo el discurso que emplea va modificando el espacio educativo hasta generar una nueva cultura virtual, en la que docentes y estudiantes se transforman en integrantes activos de ella y sus recursos. Como metodología de análisis se trabajó con el análisis mediato del discurso, propuesto por Scollon (2001), quien señaló el camino en lo pertinente a las prácticas discursivas que se llevaban a cabo en las cartografías virtuales multimodales y cómo estas afectaban lo inherente a la praxis educativa. Finalmente, luego de revisar y analizar estas prácticas sociales se obtuvieron algunas conclusiones de interés: la multimodalidad transforma el espacio educativo actual en interactivo, tanto docentes como estudiantes deben prepararse en la virtualidad y estar atentos a la cibercultura que se genera, y docentes y estudiantes se transforman en seres interrelacionales, al estar en contacto con otras intersubjetividades diversas con las cuales compartir saberes.
\end{abstract}

Palabras claves: Multimodalidad, cartografías virtuales, práctica discursiva.

Abstract: This article refers to multimodality and the educational environment. It analyzes this discipline and how the discourse it uses modifies the educational environment until it generates a new virtual culture, thus transforming students and teachers into active participants of this new culture and its resources. The mediate analysis of discourse suggested by Scollon (2008) was used as analysis methodology. There, he indicated the way related to discursive practices applied in the virtual multimodal mappings, and how they affected the educational practice. Finally, after analyzing those social practices, we reached some conclusions of interest: multimodality transforms the current educational environment into an interactive one, where teachers and students must be trained regarding virtuality and where they must be aware of the new cyberculture being generated. Teachers and students are now interrelated since

Keywords: Multimodality, multimodal practice, virtual culture.

\footnotetext{
${ }^{1}$ Este artículo fue realizado en la asignatura Discurso educativo, del doctorado de Pedagogía del Discurso del Instituto Pedagógico de Caracas (IPC) de la Universidad Pedagógica Experimental Libertador, dirigido por el doctor César Villegas.

${ }^{2}$ This article was created in the Educational Discourse course, from the Ph.D. in Discourse Pedagogy at IPC, and led by Mr. César Villegas, Ph.D.

${ }^{3}$ Profesora graduada en la especialidad de Literatura y Lengua Castellana en la UPEL-IPC, con Maestría en Literatura Latinoamericana en la misma universidad. Desarrolla tesis doctoral en la actualidad de su doctorado de Pedagogía del discurso. Directora del Instituto Venezolano de Investigaciones Lingüísticas y Literarias “Andrés Bello" y profesora de la asignatura lengua española.
} 
Una mirada desde la experiencia en aula traslada al docente hacia las diferentes maneras de asumir su práctica escolar y de interacción social con sus estudiantes. De allí que, antes de tocar multimodalidad y discurso educativo se pretende definir el primer constructo. En principio, se tomará multimodalidad como las múltiples formas de desarrollar conocimientos y saberes haciendo uso de las cartografías tecnológicas (Fainholc, 2004).

Revisando la bibliografía al respecto, la multimodalidad, a partir de la visión de Kuhn (1985), sobre ciencia normal y sobre la construcción de paradigmas, se transforma en un saber que redimensiona el espacio aula como generador de conocimiento novedoso. La multimodalidad hace uso de aplicaciones de la red de internet y estas incluyen la competencia que modifica el espacio de aprendizaje y lo cambia con las nuevas tecnologías expuestas por la plaza bajtiniana, este último término acuñado por Bajtin (2011), para referirse a los distintos contextos de discusión que giraron alrededor de las letras y la literatura y que luego es retomado por el internet para referirse a la plaza telemática (espacio de convergencias humanas, que desde la virtualidad entran en discusión). En este ámbito, el conocimiento se construye con el diálogo de múltiples intersubjetividades, creando una polifonía de voces que comparten saberes, experiencias, ideologías y posicionamientos diferentes frente a la vida y a los espacios societales tales como el educativo.

Por otra parte, esa plaza como espacio virtual crea y ofrece aprendizajes multivariados y globalizados. Lo interesante es que como praxis valora los procesos de aprendizaje que afectan al sujeto y que tienen relación con lo cognitivo, lo socio cultural, e inclusive lo afectivo (emotivo). También privilegian el constructivismo gotszkyano (Vygotsky, 1934) que le permite al sujeto construir su propio aprendizaje; una práctica pedagógica, por demás, que atiende las necesidades estudiantiles y promueve el equilibrio, el éxito y las negociaciones de saberes.

Otro aspecto importante, es que al tomar en cuenta la dimensión constructivistainterpretativa, que se concibe como el diseño de conocimiento y significado (Vygotsky (1934), se hace posible el empleo de los textos multimedias, hipermedias e hipertextos, que le permiten al sujeto enfrentarse al conocimiento y significado multimodal creado y de esa manera puede, entonces, realizar distintas clases de lectura en el ámbito tecnológico: horizontales, verticales, secuenciales y cruzadas. Así mismo, el individuo puede acercarse a la intertextualidad e interdiscursividad. En el caso del estudiantado, ya este no solo emplea el texto tradicional para acercarse al conocimiento, sino que también se acerca al entramado de redes de significación textual existente en internet y en los dispositivos telemáticos, hipervínculos, link, enlaces y otros recursos, que lo hacen un individuo multisensor. La plaza bajtiniana o telemática, conocida como campo de discusión virtual, incide en que el estudiantado se transforma en navegante de la red en un ambiente relacional donde comparte con docentes, padres y madres, compañeros y compañeras, amistades y miembros de la comunidad donde se desarrolla humanamente y profesionalmente. 
doi: http://dx.doi.org/10.15359/ree.19-2.7

URL: http://www.una.ac.cr/educare

En definitiva, la praxis multimodal está determinada, como ya se dijo, por una cartografía que le permite tanto al personal docente como al estudiantado reconocer, en la plaza telemática, un recurso para construir su andamiaje de saberes. De allí que, para analizar esta práctica social, se trabajará con las propuestas de Cabero (2006); Martos (2009); Plaz y Vessuri (2000) y (Borràs (2005).

\section{La multimodalidad desde el análisis mediato del discurso}

En esta sección del artículo, se introduce al lector en la metodología del análisis mediato del discurso propuesta por Scollon (2001), la cual permitirá estudiar la multimodalidad como una práctica social. Con esto, se producirán y generarán conclusiones sobre los cambios que, desde el discurso, logra la práctica multimodal en materia educativa y, por consiguiente, se ofrecerán algunas perspectivas sobre los desafíos que esto implica en los espacios escolares del mundo y del país.

Se describirán los lineamientos más relevantes del análisis mediato del discurso. En primer lugar, para Scollon (2001), el análisis mediato del discurso seadentra en el contexto de los problemas sociales. Ellos se pueden encontrar en los textos, relatos, televisión, periódicos e internet. En líneas generales, el análisis mediato del discurso estudio interpreta y explica los problemas sociales. Se centra en la acción social y lo interesante es que emplea el análisis crítico del discurso con la finalidad de explicar el lenguaje en uso, como medio para abordar el cambio social.

De acuerdo con Scollon (2001), el análisis mediato del discurso intenta vincular acciones sociales y discurso. En segundo lugar, el análisis del discurso atiende las relaciones de poder en la sociedad. Estas se sustentan en la práctica y la práctica se refleja a través del discurso, que es uno de los medios hacedor de cultura y que por ende se relaciona con la sociedad. En tercer lugar, usa el texto y cualquiera de los otros medios discursivos para ilustrar la acción social y asume que las representaciones textuales siempre habrán de subrepresentar los significados. Para concluir, estas subrepresentaciones se basan en la práctica: el hábito, el deseo, el juicio..., en que las acciones quedan fueran del acontecer de los actores sociales, los textos, etc. Todos actúan como instrumentos de mediación. Los pasos que definen este enfoque pueden concretarse en:

1. Los nexos de práctica: Son aquellos aspectos que vinculan unas prácticas con otras. Establecen las comunidades de práctica y estas comunidades pueden explícitas, implícitas o imaginadas.

2. El escenario de la acción: Representa el tiempo en que se manifiesta la acción mediata. Es el momento tanto espacial como temporal en que se cruzan distintas prácticas sociales.

3. Los instrumentos de mediación: Son las que apoyan o limitan las acciones. 
4. Las prácticas de mediación: Son conjuntos de acciones mediatas. Pueden interpretarse. Forman parte de la vida de los actores sociales que las realizan y se manejan como parte de un componente histórico-vivencial.

5. Los nexos de práctica: Son aquellos aspectos que vinculan unas prácticas con otras. Establecen las comunidades de práctica y estas comunidades pueden explícitas, implícitas o imaginadas.

6. La comunidad de práctica: Es el Los nexos de práctica: Son aquellos aspectos que vinculan unas prácticas con otras. Establecen las comunidades de práctica y estas comunidades pueden explícitas, implícitas o imaginadas.

La sistematicidad de estos pasos llevará al investigador hacia la experiencia multimodal, como acción que se instituye en práctica social-pedagógica. Al referenciar la multimodalidad desde ese punto de vista, se evidencia a través de ella, un discurso que da cuenta de una sociedad y una cultura, que hace un acercamiento del sujeto al conocimiento y aprendizaje, por medio de múltiples formas. Esas formas se ven acompañadas por la tecnología de punta, pero también por la competencia, por la organicidad, por el componente humano, por el componente social y por otros recursos que las complementan y las presentan en educación como aportes didácticos que interrelacionan saber, sujeto docente y estudiante. Valdría la pena citar a Barrera (2008), "la internet llegó para quedarse" (p. 40), y se podría decir que la multimodalidad es la práctica que se género como apoyo y aporte a la educación.

Luego de haber explorado la metodología que se aplicará al análisis de los textos, es necesario señalar que se seleccionaron textos y no otro tipo de (cartografía) material, ya que se constituyen en una fuente legaly de interés sobre la red. Por otra parte, porqueal ser instrumentos de mediación harán énfasis en la multimodalidad como praxis pedagógica. Estos textos, como herramientas cargadas de signos al explorar la multimodalidad, hacen hincapié en una cibercultura, que a partir del ejercicio social construyen con la participación colectiva una sociedad escolar interactiva, cuyas fronteras fluctúan creando constante conocimiento. Un aspecto de interés que se debe resaltar es que fueron cuatro textos, porque contemplaban el eje medular de lo que es y representa la multimodalidad y eso se constituía en la internet o cartografía de red y su praxis en aula.

A continuación, textos y tópicos sobre los que hablan "Bases pedagógicas del e-learning" de Cabero (2006), que se refiere a la pedagogía que la internet sigue para hacer del navegante de la red un experto. También habla del empleo por parte del sujeto de la multimodalidad, no solo como hecho tecnológico, sino como hecho que le permite manejarse desde la competencia lectora, escritural, reflexiva y a partir de otros aspectos relacionados con diversas textualidades electrónicas y no electrónicas; "Tecnología de la palabra en la era digital: De la cultura letrada a la cibercultura" de Martos (2009), este texto hace referencia a cómo la cultura del libro se 
doi: http://dx.doi.org/10.15359/ree.19-2.7

URL: http://www.una.ac.cr/educare

transforma en un cibercultura a la que todo conocedor y usuario debe accesar, ya que representa lo que tiene que ver con las nuevas literaturas electrónicas; "La telematización de la educación superior en Venezuela, entre la equidad y la exclusión" Plaz y Vessuri (2000), texto que analiza cómo ha sido la acogida de lo telemático en la educación superior en Venezuela y "Teorías literarias y retos digitales" de Borràs (2005), donde se recoge el proyecto Hermeneia, que estudia con amplitud las cartografías de la red.

\section{Multimodalidad: Múltiples visiones}

Al analizar los textos seleccionados se deben resaltar las ideas más importantes de cada uno. Por ello se empezará con Cabero (2006), quien en su texto plantea que el e-learning como estrategia mediática resuelve muchos problemas educativos y de tiempo, al introducir al sujeto en un mundo interactivo, donde todo sucede en microsegundos. El autor considera que esta estrategia toca o refiere aspectos de interés como son el campo tecnológico, el de conocimiento y el metodológico. El primero hace uso de las cartografías de la red, el segundo, de los saberes que se imparten a través de la red y el tercero, a través de los recursos con los que cuenta la red para transmitirlos. El e-learning requiere de los aspectos multimodales: interactividad e hipertextualidad. Tanto docentes como estudiantes tienen que estar altamente motivados para desarrollar la estrategia, quienes enseñan con el e-learning deben pertenecer a la sociedad del conocimiento que se nutre de las nuevas cartografías. Deben ser personas activas, innovadoras y creativas. En todos los niveles deben ser líderes académicos al dar a conocer estas tecnologías, ya que presencial o virtual, las escuelas, liceos, y universidades se deben desarrollar con eficiencia, por personas conocedoras de la estrategia. Con el e-learning es importante desarrollar el aprendizaje colaborativo o cooperativo, de esa manera se crea la comunidad de praxis virtual.

Por su parte, Martos (2009) considera que el internet es una forma de digitalizar la palabra y, por tanto, para ello la red ha creado sus propios instrumentos y artefactos culturales, desde la mensajería electrónica hasta las representaciones de otras cartografías, como la fílmica. Martos asume que la escuela tiene un papel importante al manejar el discurso de la cibercultura letrada frente a sus estudiantes, ya que de ella depende que estos sujetos se sirvan de la red como herramienta, como estrategia y como complemento en el manejo y adquisición de saberes. Este investigador expone que las nuevas cartografías establecen la pluralidad de alfabetismos o nuevas alfabetizaciones, de nuevas lecturas que hace el estudiantado de la escuela. Las lecturas que se mencionan van de la tradición netamente escrita a las que requieren las nuevas cartografías de la red, sobre todo las audiovisuales. Debe existir para Martos una mirada conciliadora entre el mundo de las letras y la cibercultura letrada. Martos se pronuncia por la tecnología del intelecto, la cual permite reescribir, repensar y reajustar sus procesos de aprendizaje al individuo y por otra parte lo ayuda a valorar sus procesos de lectura, conversacionales y escriturales. Hay que decir que la tecnología a la que hace referencia el 
doi: http://dx.doi.org/10.15359/ree.19-2.7

URL: http://www.una.ac.cr/educare

CORREO: educare@una.cr

investigador potencia la praxis de aprendizaje cognitiva y social. Es decir, que ayuda a construir el pensamiento y la identidad social colectiva. Por tanto, al sujeto se le debe entrenar en el uso de las nuevas tecnologías: diarios, blogs, web blog..., igualmente, en el acercamiento a las expresiones cinematográficas, videos y otras cartografías. En estas lides, Martos sugiere las prácticas colaborativas y cooperativas al acercar al estudiantado a estos elementos de práctica social novedosos: libre acceso al conocimiento, nuevos valores, puentes entre la cultura letrada clásica y la digital, pluralidad de lecturas, abanico de actividades etc. Sin embargo, la cultura letrada tradicional, para el estudioso revisado, permanece y al permanecer se conecta con la cultura digital y forma una cultura de convergencia o híbrida.

Alrespecto, no podíanfaltarlasideas dePlazyVessuri(2000) sobrelosproyectos detelematización de la educación, sobre todo a nivel superior en Venezuela. Lo interesante de este proyecto es que se desarrolla en América Latina y el Caribe, porque se aspira formar en los países inscritos en este continente, una ciudadanía competitiva internacionalmente. Las redes creadas por este proyecto en Venezuela, específicamente son REACIUM o Red Académica de Centros de Investigaciones y Universidades Nacionales y el CONICIT o Consejo Nacional de Investigaciones Científicas y Tecnológicas. Como tales, estos proyectos, con el paso de los nuevos gobiernos y políticas de administración, investigación y educación, se han modificado; pero es necesario saber cómo se formaron, ya que dieron paso a una nueva disposición del internet y uso de la red, sobre todo en el campo educativo. Ahora bien, continuando con los proyectos de REACIUN Y CONICIT, estos son apoyados por la CEPAL y la UNESCO, ya que se busca con ello, ingresar a todo el estudiantado venezolano a la red para que sea participante activo, con la finalidad de promover la equidad en el uso de las TIC y en el desarrollo de sistemas de información, para el provecho de la comunidad académica regional y creación de redes telemáticas académicas. El funcionamiento de las TIC implica el ejercicio de una ciudadanía auténtica, es decir, que los ciudadanos y ciudadanas aprenden a aprovechar las plataformas de telecomunicaciones. Lo verdaderamente interesante de lo planteado por Plaz y Vessuri radica en que a partir de los años noventa en Venezuela se empiezan a implantar las redes telemáticas y se crea la red de la academia nacional que va a beneficiar a toda aquella persona venezolana que se prepara y educa en el país. Los usuarios y usuarias debían formarse en las TIC desde las premisas de expectativa, valoración y motivación que les acerca al uso de link, hipervínculos, blog, web blog y otros recursos que empezaban a gestarse en las redes.

Al cierre de todos estos planteamientos se encuentra el proyecto Hermeneia, explicitado en el libro Textualidades electrónicas: Nuevos escenarios para la literatura y presentado por Borràs (2005). Hermeneia es un plan internacional de investigación sobre las aplicabilidades de los recursos de la red y estos son: textualidades electrónicas, la sociedad de información, cartografías de la red, la escritura y la lectura electrónica en la plaza de la red y las necesidades de enseñar a leer críticamente en la red. Como proyecto es colectivo y agrupa a una serie de investigadores serios que han venido atendiendo a los diversos cambios que se han dado en la manera de consumir, de relacionarse, de informarse, de 
doi: http://dx.doi.org/10.15359/ree.19-2.7

URL: http://www.una.ac.cr/educare

crear, de amar, e incluso de aprender con los avances tecnológicos que propician el uso de internet y las TIC. Este grupo aboga, claramente, por una nueva forma de abordar el texto y la literatura. La docencia ejerce un papel bien definido en ese abordaje, pero también hay dos aspectos a parte del docente, que no deben descuidarse: la valoración de la composición-la recepción y la recepción del texto-lo literario. En este contexto Hermeneia hace crítica constante de la texturización, de su práctica y de sus formas de difusión, para lo cual se emplea la estructura de los cibermapas compuestos por diversas categorías que permiten visualizar el estado de texturización en la red. Este estado, sin embargo, no es permanente, ya que la red está en constante cambio y movilidad. Hermeneia como proyecto tiene unos parámetros significativos, porque monitorea desde la construcción de saberes, la instauración, el afianzamiento y la aplicabilidad de las competencias requeridas por el espacio de la tecnologización y texturización multimodal.

Demás está decir que para Borràs (2005) y los otros investigadores del proyecto, el espacio de la texturización multimodal conduce al sujeto que aprende desde Hermeneia al conocimiento y uso de las textualidades electrónicas que surgen por la sociedad de información de internet. Esas textualidades ofertan distintos tipos de lecturas para estos navegantes de la red: intertextual, relación de un texto con otro, e hipertextual, que a su vez multiplica la relación textual en vertical, direccional y lateral. El personal docente debe formarse en estas textualidades electrónicas y, por tanto, poseer unas competencias lectoras, escriturales y crítico-reflexivas sólidas que le permitan ser no solo hábil, sino un participante protagónico y activo que pueda seleccionar, hacer enlaces, comunicarse e intercambiar con otras intersubjetividades, en especial la de sus estudiantes. Por ello, las textualidades electrónicas establecen un vínculo entre el texto y lo electrónico, que permite el acercamiento del personal docente y del estudiantado a una literatura digital; o que se maneje con soportes digitales. En fin, en esta textualidad electrónica se encuentran desde los blogs hasta los hipertextos de ficción, los hipermedia, los multimedias y los art poetry. Considerando lo anterior, Borràs (2005) expresa que la experiencia cartográfica lleva al docente a conectarse con una lectura y escritura diferente en la red. Una lectura en colectivo, una lectura participativa. Así mismo, le permite conocer las disposiciones sobre lectura y escritura que la red le otorga como usuario. Es de hacer notar que leer y escribir a partir del hipertexto hace de esa actividad un espacio social donde los saberes se diversifican, se cotidianizan y se acercan al internauta.

Resumiendo, para Cabrero (2006), la multimodalidad es una estrategia virtual; para Martos (2009) es una red de instrumentos y artefactos culturales; para Plaz y Vessuri (2000) es un proyecto telemático, y para Borràs (2005) es una herramienta holística porque integra lo estructural, lo lingüístico, lo técnico y lo simbólico, relacionado con lo comunicativo y el lenguaje. Ella guía a docentes en formación a conocer e interactuar con los espacios de enseñanza virtual, donde las TIC son un apoyo que les permite desarrollar competencias lectoras, escriturales, reflexivas, valorativas e inclusive afectivas en los estudiantes. 
doi: http://dx.doi.org/10.15359/ree.19-2.7

URL: http://www.una.ac.cr/educare

CORREO: educare@una.cr

\section{Entramado de la multimodalidad}

El análisis de los artículos anteriores se iniciará con las máximas y principios en los que se sustenta la internet y las nuevas formas de leer, mirar y explorar en la red, las cuales se permiten formar a internautas como personas expertas, que pueden hacer uso de la multimodalidad, como hecho tecnológico y como hecho que las acerca a las nuevas literaturas electrónicas. Tanto Cabero (2006) como Martos (2009) y Plaz y Vessuri (2000) parten de estas máximas o principios. Así mismo, el proyecto Hermeneia, tomado del libro Textualidades electrónicas: Nuevos escenarios para la literatura (Borràs, 2005) las contempla. Ellas se presentan dentro del campo lingüístico como oraciones declarativas y lo interesante es que cada una genera una lección, que afianzará el uso del internet y la multimodalidad en los individuos.

A continuación las máximas y principios:

Internet anima el contacto con la facultad, facilita la cooperación entre pares, facilita el aprendizaje activo, implica el feedback rápido, pone énfasis en el tiempo de las tareas, comunica las expectativas de los participantes y respeta el talento y los caminos del estudiante. Luego, las lecciones que genera la praxis de internet son: ofrece claridad en la interacción de los estudiantes, ofrece aprendizajes significativos al estudiante, presenta proyectos por parte de los alumnos, ofrece fedback para el estudiante en red sobre el conocimiento que maneja, ofrece diversidad de cursos para el estudiante, provoca el estímulo en el estudiante a realizar sus tareas y desarrollar su comunicación, permite al estudiante el hacer uso de su experiencia, frente a los conocimientos y saber que le transmite (Pallof et al., 2003, citado en Cabero, 2006).

A propósito de estas máximas y principios se muestran resaltados en negritas los núcleos de interés de las oraciones declarativas; sin embargo, hay que acotar que todos los principios y máximas van con los verbos: animar, facilitar, implicar, poner, comunicar y respetar y las lecciones con los verbos: ofrecer, presentar, provocar y permitir. Hecho que parece interesante, porque los verbos de las máximas las presentan como una gran afirmación que rige y le da forma a la internet y al espacio multimodal. Los verbos de las lecciones hablan de que las premisas se complementan con una respuesta por la misma acción que genera esta y que les permita a internautas que están aprendiendo a navegar, usar los contextos anteriores (internet y multimodalidad) con libertad y pluralidad.

En otro orden de ideas, el conjunto de máximas y lecciones son acciones que se suceden en la red en un tiempo no convencional, que solo le pertenece al individuo internauta (estudiante) que aprende y a la persona mediadora (docente) que enseña. El hecho de repetir estas acciones una y otra vez, en el marco de una comunidad, por diversos usuarios las hace práctica social instituida. Tanto estudiante como docente, mediador en la praxis social representada por las premisas y lecciones, 
doi: http://dx.doi.org/10.15359/ree.19-2.7

URL: http://www.una.ac.cr/educare

leen, miran, exploran, experiencian y negocian (e-learning), en la red empleando la mutimodalidad. Es aquí donde el discurso generado por estas representaciones lingüísticas incorpora a estudiantes, docentes y usuarios al espacio de práctica comunitaria telemática, virtual o bajtiniana.

La multimodalidad se ubica, pues, estratégicamente en la comunidad bajtiniana y se transforma en puerta de entrada a nuevas miradas en torno al conocimiento. Miradas que promueven la virtualidad, interactividad e hipertextualidad: pero, también, desde la competencia en lectura crítica, escritura, reflexión, organización, etc. Esta competencia le permite a los navegadores y a las navegadoras (estudiantes y docentes-mediadores), construir su andamiaje de saberes y de interacción social. De esta forma, la multimodalidad actúa en concordancia con el e-learning, predominando un binomio que estimula una práctica social pedagógica activa, eficiente, disciplinada y motivadora. Por tal razón, esta práctica social y pedagógica que parte de las máximas, premisas y lecciones de Cabero (2006); Martos (2009); Plaz y Vessuri (2000) y Borràs (2005) puede enmarcarse dentro de la teoría que describe el discurso educativo a través de la teoría del emprendedorismo educativo (EE) propuesto por Fischman y Haas (2011). El emprendedorismo educativo apoya los cambios estructurales que se deben hacer para instaurar nuevas prácticas educativas y promueve la necesidad de que existan dirigencias académicas eficientes, para llevarlas a cabo. De acuerdo con ello, citando a Cabero (2006):

Si queremos incorporar [la práctica del] e-learning [y por tanto de la multimodalidad] tendremos que tener dirigentes académicos que se desenvuelvan en la sociedad del conocimiento y no en la postindustrial. Tendremos que tener líderes académicos que jueguen con la innovación, la creatividad y el riesgo como principios gestores, y no con el miedo ... que todo cambio genera ... ( p. 8).

Es decir que, para los autores estudiados, el emprendedorismo educativo (EE) constituiría un discurso que valida la multimodalidad y para este constructo es importante un aprendizaje colectivo y a la vez de calidad.

\section{Multimodalidad: práctica social y pedagógica}

Lo establecido hasta ahora presenta a la multimodalidad como una práctica social negociar, pero esta a su vez desarrolla prácticas sociales que se interconectan y vinculan unas con otras, mediante los nexos lingüísticos de la red: link e hipervínculos. Las prácticas que se vinculan crean las llamadas cartografías y mapas de textualidades en la red. Estas cartografías deben manejarse desde la pericia de internautas-usuarios (estudiantes y docentes) y como lo fundamentan Borràs (2005) y Fainholc (2004), esta última, quien también hacen grandes aportes al proyecto Hermeneia, aludido en el capítulo I (Teorías literarias y retos digitales) de Textualidades electrónicas: Nuevos escenarios para la literatura. 
Las representaciones cartográficas, al vincularse, dan paso al encuentro de distintas intersubjetividades en la gran plaza telemática o bajtiniana, ya que permiten el diálogoyla construcción de nuevos espacios virtuales de conocimiento. De ello puede deducirse que permite la praxis de la convivencia social, donde personas usuarias (estudiantes-docentes) intercambian información, ideas, reflexiones, opiniones e inclusive experiencias. Este encuentro de intersubjetividades diversas da paso a una cibercultura que se pasea por toda la red, a través de las distintas páginas web, web blog y otras textualidades electrónicas como las manejadas por la intertextualidad, hipertextualidad y la multitextualidad. Las textualidades electrónicas mencionadas siguen siendo parte de la práctica social pedagógica que representa la multimodalidad.

Ahora bien, cuando se aplica a los textos seleccionados el análisis mediato del discurso de Scollon (2001), se encuentra una acción mediata del discurso recurrente en todos ellos. La acción a la cual se alude en cada texto es la de que la multimodalidad abre un espacio de convergencia de conocimiento en la plaza telemática. Este se nutre de diversos elementos tecnológicos (dispositivos digitales textuales) que hacen que la comunidad virtual participante de esos espacios requiera de los llamados ejes. Los ejes representan los escenarios de acciones lingüísticas y literarias desplegados en la interacción multimodal, que se desarrolla a través de los componentes textuales empleados por internet. Los dispositivos digitales textuales necesitan ser abordados por escritores y lectores críticos. La combinación de todos estos aspectos permite una práctica continua de los usuarios y navegantes de la red, estudiantes y docentes.

Másadelanteseencuentran los recursosy los instrumentos delosquesevale la praxis multimodal y que están formados por las textualidades electrónicas de las cuales disponen los usuarios virtuales: multimedia, hipermedia, hipertexto, hipertexto de ficción e inclusive el art poetry (texto poético distribuido artísticamente como mapa de conocimiento). Como componentes de la práctica social se organizan atendiendo a lo histórico, lo social, lo literario, lo ideológico, lo simbólico, lo tradicional y lo cultural. Este conjunto de elementos en la plaza telemática se organiza desde la pluralidad de voces participantes, que confrontan sus ideas, permitiendo la aparición de nuevos paradigmas sociales y culturales. Ejemplo de ello son googles, facebook y twitter. Hay que comentar que la pluralidad de voces determina un ámbito social que fluctúa entre signos e imágenes.

De esta manera se crea una extraordinaria fragua lingüística y cultural de la que quienes navegan (estudiantes y docentes) se sirven para realizar distintas prácticas. Esta fragua exige, por parte de los usuarios, un conocimiento y lectura crítica, como ya se ha dicho con antelación, de las e-literatura o discursos de la red. Atendiendo a esta lectura reflexiva los internautas pueden ser cartógrafos competentes en tecnología comunicativa y estratégica. Los lectores de la red deben ser navegantes intencionales, en otras palabras que sean conscientes del uso del contexto virtual y sus recursos. Así mismo, del conocimiento y saberes que generan las cartografías de la plaza bajtiniana.

Resumiendo, los constructos revisados hasta el momento dan cuenta de que la comunidad de intersubjetividades que opera en la plaza telemática instaura una cultura digital o una cibercultura. 
doi: http://dx.doi.org/10.15359/ree.19-2.7

URL: http://www.una.ac.cr/educare

En esta cibercultura la manera de abordar el conocimiento es diferente a la forma como se hace tradicionalmente. Es decir, haciendo uso de las lecturas eferentes o literarias. Por el contrario, las lecturas que se realizan en la red son horizontales, verticales y cruzadas por el uso de las herramientas, tales como link o hiperlink. En fin, existe mayor variedad de prácticas en internet que le permiten al sujeto acercarse a la información y conocimiento. Es interesante acotar que la cibercultura que se crea a través de la red es incluyente, les permite a las culturas subalternas: mujeres, afrodescendientes y aborígenes, participar del universo telemático que ofrece la textualidad cartográfica electrónica, asignándoles nuevas identidades y, por si fuera poco, atendiendo la multiculturalidad.

Es aquí desde el epicentro de la cibercultura digital, que la multimodalidad expone para el internauta (estudiante-docente), la posibilidad de ingresar al mundo íntimo del espacio letrado $y$, desde allí, se le permite reconocer la subjetividad que al comunicar y expresar se transforma en intersubjetividad compartida, como mejor lo referencia Martos (2009), en cultura del diálogo o en inteligencia que dialoga. La inteligencia que dialoga reconoce la diferencia entre un valor y su contrario y, por ello, la multimodalidad y sus distintas miradas del hecho educativo le dan prioridad al aprendizaje libre, en el que confluyen voces, herencias, y propuestas diversas, pero no solo eso, sino que permite a los navegantes de la red apropiarse de internet como apoyo tecnológico y como hecho socio-cultural. Esto ocurre porque la red está en permanente construcción y renegociación de sus espacios y porque la red no tiene fronteras físicas, ni centros, ni periferias, ni arriba, ni abajo, ni adentro, ni afuera y mucho menos pasado y futuro. Es importante destacar el papel del usuario, tanto docente como estudiante, en este proceso, porque debe tener capacidad de análisis y síntesis, debe saber negociar conflictos, desarrollar trabajo en equipo, ser creativo e innovador, tener capacidad de aprender y desaprender, tener buena comunicación y poseer inteligencia emocional. También debe ser responsable para que sus estudiantes sepan aceptar los pro y los contra de una cultura digital. Por su parte, el estudiantado-usuario debe estar dispuesto a construir su propio aprendizaje. En definitiva, tanto docente-usuario, como estudiante-usuario, según Martos (2009), ante una cultura híbrida deben tener una actitud crítica para vivir en medios diferentes; una disposición que les permita recurrir y resumir lo más significativo de ambos mundos, por ejemplo, las formas culturales clásicas o emergentes de la era digital.

Especial atención merece el proceso y el discurso de la digitalización o telematización en Venezuela, especialmente en la universidad, según Plaz y Vessuri (2000) se ha manejado entre equidad y exclusión. Desde el encuentro de los países latinoamericanos en el regional de la Habana y, por supuesto referenciado este por el informe Bienal de la UNESCO (1998), a fin de patrocinar proyectos relacionados con la telematización de la educación, privilegiando las categorías sociales que más las necesiten se ha presenciado cómo estos espacios virtuales auspician solo lo tecnológico y descartan la propuesta de variedad de miradas que ofrecen las cartografías existentes en la red. Es decir, que de la multimodalidad solo pareciera interesar lo técnico y no el conocimiento que se genera en la plaza bajtiniana como entorno de convivencia social. Tomando en cuenta esa perspectiva, se hace necesario establecer una práctica continua que transforme el saber multimodal en acción multimodal. 
En Venezuela se privilegia el uso de la TIC y a partir del CONICIT (hoy ONCTI), se lideran proyectos parauso del internety del intranet, conocidos como REACIUM, UNIXySAICYT. Estos proyectos han venido gestándose a partir de 1989, hasta la presente fecha. Su finalidad se dirige solo al elemento técnico, que radica en instalar sistemas de información. Si se contempla de esta manera la multimodalidad, en el sistema educativo en Venezuela, se puede decir que ella excluye a gran parte de los usuarios (docentes y estudiantes), de la convivencia socio-cultural que promueve la plaza bajtiniana, porque, el uso de la red solo se limita, en ocasiones, a lo técnico. En relación con la equidad podría verse reflejada en los esfuerzos que hace la UNESCO (1998) para lograr en los países latinoamericanos, en educación, verdaderos espacios de convivencia histórica, social y cultural. La visión de Plaz y Vessuri (2000), sobre multimodalidad, se maneja dentro de la nostalgia académica (NA) y dentro del emprendedorismo académico (EE). La primera postura, cuando ven que en la educación latinoamericana, este implante de nuevos sistemas de información y redes digitales abriría un nuevo campo de acción a los actores excluidos, como los de Un mundo feliz, referenciado por Huxley (1970), y la segunda postura, cuando ven el mismo problema como parte de la aspiración de fomentar una ciudadanía auténticamente nueva, competitiva, tecnológica, libre, reflexiva y crítica.

A pesar de lo anterior, Plaz y Vessuri (2000) hacen un aporte interesante en el caso de Venezuela y es que se intenta construir una red académica nacional, aún cuando hasta el momento, solo se manejan las TIC y los dispositivos que se convertirán en ganancia para la praxis multimodal, porque cada universidad, a través de sus diversas plataformas tecnológicas, contribuirán en la formación de redes y mapas cartográficos que generarán darán paso a los navegantes de la red educativa.

En definitiva, para Venezuela y latinoamericana se aboga porque la multimodalidad verdaderamente sea un espacio de la institución educativa, porque asuma su compromiso social y cultural, porque sea plural, porque sea un eje transformador del sujeto, porque genere competencias comunicativas y organizacionales. Y lo más importante, que las nuevas cartografías de conocimiento sean determinadas por el espacio público.

La dinámica de los espacios públicos reagrupa a los actores sociales desde el punto de vista de la estrategia que determina aspectos como la lectura y la escritura en la red; también la reflexión y, sobre todo, ese manejar la intersubjetividad de otros, tan necesaria en los espacios educativos en construcción o en los espacios multimodales educativos.

\section{Consideraciones finales, desafíos y reflexiones}

Existen dos grandes desafíos para la multimodalidad:

- Convertirse en espacios de convergencia y diversidad educativa, donde el conocimiento genera desde la práctica y la acción social, un verdadero cambio cibercultural. 
doi: http://dx.doi.org/10.15359/ree.19-2.7

URL: http://www.una.ac.cr/educare

CORREO: educare@una.cr

- Hacer, a partir del discurso de la multimodalidad, una educación interactiva, donde en la plaza telemática se proyectan diversos saberes y conocimientos de participantes y las diversas intersubjetividades con las que se interrelacionan.

Las reflexiones en relación a la multimodalidad son diversas. Entre ellas:

- Como didáctica, la multimodalidad genera diversas expectativas, porque hace uso de las competencias lectoras, escriturales, reflexivas y organizativas para que el sujeto de aprendizaje construya un conocimiento virtual y dinámico.

- La multimodalidad se basa en el mapeo y la construcción de cartografías de conocimiento. Es decir, que el sujeto de aprendizaje, al navegar en la red, tiene acceso a un gran sistema comunicativo intercultural.

- La multimodalidad como acción y práctica social construye un saber para la conviviencia y para el intercambio cognoscitivo y experiencial entre distintos sujetos y espacios societales.

- La multimodalidad genera nuevas textualidades que representan tanto la cultura letrada como la nueva cibercultura.

- El discurso de la multimodalidad incluye la arquitectura de la multimedia, hipertexto, hipermedia y la relevancia de los dispositivos: link hiperlink, actuando sobre ellos.

- El discurso multimodal en educación, les permitirá al personal docente acercar a sus estudiantes a una práctica social fluctuante, que se enriquece constantemente y al estudiantado lo ayuda a vivenciar, de cerca, las nuevas situaciones cognoscitivas, afectivas y práxicas interactivas.

\section{Referencias}

Bajtin, M. (2011). Las fronteras del discurso. Buenos Aires: Las cuarenta.

Barrera, L. (2008). Habla pública, internet y otros enredos literarios. Caracas: Equinoccio.

Bolívar, A. (2008). Didáctica y curriculum: De la modernidad a la postmodernidad. Málaga: Ediciones Aljibe.

Borràs, L. (2005). Teorías literarias y retos digitales (Cap. I). En L. Borràs (Ed.), Textualidades electrónicas: Nuevos escenarios para la literatura (pp. 23-78). Barcelona: UOC

Cabero, J. (abril, 2006). Bases pedagógicas del e-learning. Revista de Universidad y Sociedad del Conocimiento, 3(1), 1-10. Recuperado de http://www.uoc.edu/rusc/3/1/dt/esp/cabero.pdf 
Fainholc, B. (2004). Lectura crítica en internet: Análisis y utilización de los recursos tecnológicos en educación. Santa Fe, Argentina: HomoSapiens. Recuperado de http://www.terras.edu.ar/ aula/tecnicatura/3/biblio/FAINHOLC-Beatriz-La-necesid.pdf

Fischman, G. E. y Haas, E. M. (2011). Nostalgia, emprendedorismo y redención: Modelos discursivos sobre la universidad. RIES, 2(3), 3-34. Recuperado de http://ries.universia.net/article/ view/42/nostalgia-emprendedorismo-redencion-modelos-discursivos-universidad

Huxley, A. (1970). Un mundo feliz. Buenos Aires: Salvat.

Kuhn, T.S. (1985). Laestructura de las revoluciones científicas. México: Fondo de Cultura Económica. Recuperado de http://www.conductitlan.net/libros y lecturas basicas gratuitos/t s kuhn la estructura de las revoluciones cientificas.pdf

Martos, A. E. (2009). Tecnología de la palabra en la era digital: De la cultura letrada a la cibercultura. Revista Latinoamericana de Tecnología Educativa, 8(2), 15-37. Recuperado de http://mascvuex.unex.es/revistas/index.php/relatec/article/viewFile/529/419

Plaz, I. y Vessuri, H. (2000). La telematización de la educación superior en Venezuela, entre la equidad y la exclusión. Educación Superior y Sociedad, 11(1-2), 157-180. Recuperado de http://ess.iesalc.unesco.org.ve/index.php/ess/article/view/363/302

Scollon, R. (2001): Acción y texto: Para una comprensión conjunta del lugar del texto en la (inter) acción social, el análisis mediato del discurso y el problema de la acción social (Capítulo 7). En R. Wodak y M. Meyer (Comps.), Métodos de análisis crítico del discurso (pp. 205-266). Barcelona: Gedisa.

UNESCO. (1998).Informe 1996-1997 de la Oficina UNESCO-Caracas. Caracas: CRESALC. Recuperado en http://unesdoc.unesco.org/images/0014/001495/149506sb.pdf

Vygotsky, L. (1934): Pensamiento y lenguaje: Teoría del desarrollo cultural de las funciones psíquicas. Buenos Aires: La pléyade. Recuperado de http://www.academia.edu/6557906/ PENSAMIENTO Y LENGUAJE Teor\%C3\%ADa del desarrollo cultural de las funciones ps\%C3\%ADquicas

\section{Cómo citar este artículo en APA:}

Santamaría, D. M. (Mayo-agosto, 2015). Multimodalidad y discurso educativo. Revista Electrónica Educare, 19(2), 105-118. doi: http://dx.doi.org/10.15359/ree.19-2.7

Nota: Para citar este artículo en otros sistemas puede consultar el hipervínculo "Como citar el artículo" en la barra derecha de nuestro sitio web: http://www.revistas.una.ac.cr/index.php/EDUCARE/index 